\title{
Rancangbangun Starter Elektrik Portabel untuk Mesin Traktor Tangan
}

\author{
Design Of Portable Electric Starter for Hand Tractor Machine \\ Geraldo Adinugra Rimartin ${ }^{1,2^{*}}$, Bambang Purwantana ${ }^{2}$, R. Radi ${ }^{2}$ \\ ${ }^{1}$ Politeknik Pembangunan Pertanian Yogyakarta - Magelang (Kampus Yogyakarta), \\ Jl. Kusumanegara No. 2, Umbulharjo, Yogyakarta 55176, Indonesia, \\ 2Departemen Teknik Pertanian dan Biosistem, Fakultas Teknologi Pertanian, Universitas Gadjah Mada, \\ Jl. Flora No. 1, Bulaksumur, Yogyakarta 55281, Indonesia \\ *Penulis korespondensi: Geraldo A.R., Email: geraldo.rimartin@gmail.com
}

Tanggal submisi: 19 Juni 2019; Tanggal penerimaan: 18 Oktober 2019

\begin{abstract}
ABSTRAK
Hingga hari ini, petani di Indonesia masih menggunakan engkol tangan untuk menghidupkan mesin traktor tangan. Hal ini dapat membuat operator kelelahan serta berpotensi menimbulkan kecelakaan kerja. Penelitian ini bertujuan untuk merancang bangun starter elektrik dengan konsep portabel. Selain itu, juga untuk mengevaluasi kinerja dari rancangbangun tersebut. Kebutuhan kecepatan putar (n) minimal serta torsi $(T)$ awal melalui perlakuan dekompresi dan tanpa dekompresi digunakan sebagai dasar untuk menghitung kebutuhan daya $(P)$ minimal. Hasil kebutuhan daya $(P)$ minimal masing-masing diperoleh sebesar 572,78 watt $(\approx 0,74 \mathrm{hp})$ dan 841,75 watt $(\approx 1,09 \mathrm{hp})$. Hasil tersebut digunakan sebagai dasar dalam menentukan komponen utama, yaitu baterai/aki 12 volt jenis basah dan motor starter arus searah (DC) jenis seri. Berikutnya, menentukan komponen pendukung, mekanisme penggerak, serta konsep starter elektrik portabel. Rancangbangun diwujudkan melalui proses konstruksi dan perakitan. Uji kinerja dilakukan terhadap prototipe. Hasil uji kinerja dari perlakuan tanpa dekompresi menunjukkan kebutuhan waktu kerja sebesar 1,88 detik, beban kerja (operator) sebesar 264,56 Joule, kecepatan putar sebesar 363,20 rpm serta daya sebesar 0,68 watt jam. Secara keseluruhan, hasil tersebut menyatakan bahwa penggunaan starter elektrik portabel lebih baik dibandingkan engkol tangan. Penelitian ini juga membuktikan bahwa penggunaan starter elektrik portabel melalui perlakuan dekompresi lebih diutamakan.
\end{abstract}

Kata kunci: Rancangbangun; starter elektrik; portabel; traktor tangan; mesin diesel

\begin{abstract}
Indonesian farmers used to utilize crank to turn on hand tractor machine till today. It may make operators weariness and potentially raised work accident. The purpose of this study was to design a portable electric starter for hand tractor machine. Moreover, the study was addressed to evaluate the performance of the design. The minimum rotational speed $(n)$ and initial torque $(T)$ in decompression and non decompression conditions were adopted to calculate the minimum power $(P)$ requirement. The minumum power of decompression and non decompression were 572.78 watts $(\approx 0.74 \mathrm{hp})$ and 841.75 watts $(\approx 1.09 \mathrm{hp})$, respectively. These values used as a reference in determining the main components, namely the wet type 12 volt battery and the serial type direct current starter motor. The next step, set up additional components, transmission mechanism, as well as concept of portable electric starter. The design was realized by construction and assembly process. A performance test was carried out on the prototype. The performance test of non decompression showed 1.88 seconds for working time, 264.56 Joules for workload (operator), $363.20 \mathrm{rpm}$ for rotating speed and 0.68 watt hours for power requirement. Overall, application portable electric starter indicated better performance than crank. This study proved a high preference of operator on application of portable electric starter in decompression conditions.
\end{abstract}

Keywords: Design; electric starter; portable; hand tractor; diesel engine 


\section{PENDAHULUAN}

Berdasarakan data dari Kementerian Pertanian RI (2018), alat dan mesin pertanian (alsintan) yang paling banyak dihibahkan kepada petani Indonesia adalah traktor tangan. Jumlah total 112.395 unit traktor tangan pada rentang tahun 2013 - 2017. Pada setiap kali proses starting untuk menghidupkan mesin traktor berdaya maksimal 10,5 hp dibutuhkan input energi minimal sebesar 627,80 Joule (0,17 watt jam), yang dapat mengakibatkan operator kelelahan. Menurut Nugraha (2016), penggunaan engkol tangan juga berpotensi menimbulkan kecelakaan kerja bagi operatornya. Prosentase kecelakaaan 9\% karena engkol tangan berbalik arah sehingga mengenai bagian muka operator. Penelitian ini bertujuan untuk merancangbangun sebuah prototipe starter elektrik sebagai upaya dalam mencari alternatif solusi pengganti engkol tangan agar dapat mempermudah kerja serta mencegah kecelakaan kerja bagi operator pada saat menghidupkan mesin traktor tangan.

Secara umum starter elektrik terdiri dari baterai/ aki, sekering (fuse), kunci kontak (ignition switch), saklar magnet starter (relay starter), saklar starter (starter switch) dan motor starter (Meicipto dkk., 2015). Rancangbangun starter elektrik diusahakan tidak mengubah komponen yang sudah terangkai pada mesin traktor tangan. Alasan utamanya agar dapat digunakan untuk traktor tangan serta alsintan lainnya yang spesifikasinya sesuai dengan kebutuhan penggunaan, atau dengan kata lain berkonsep portabel. Konsep ini diusulkan untuk menghemat energi, biaya dan waktu. Salah satu cara yang dapat dilakukan untuk mewujudkan konsep portabel dimaksud adalah dengan memodifikasi engkol tangan yang ada pada mesin traktor tangan. Engkol tangan merupakan sebuah komponen yang terpisah dari rangkaian mesin traktor tangan. Apabila dimodifikasi, maka tidak akan mengubah komponen lainnya yang sudah terangkai pada mesin traktor tangan.

Nugraha (2014) menjelaskan beberapa tahapan dalam proses analisis motor starter pada suatu mesin. Pertama, mengukur/menghitung kebutuhan kecepatan putar minimal, torsi awal, dan daya minimal. Kedua, mendesain dan menganalisis material yang akan digunakan. Najib (2013), mekanisme penggerak pada sebuah mesin ada 3 macam: i) menggunakan gear (timing gear), ii) rantai (timing chain), dan iii) sabuk (timing belt). Pada penelitian ini, mekanisme penggerak yang digunakan adalah timing gear karena jarak antar komponennya berdekatan.

\section{METODE PENELITIAN}

\section{Lokasi Penelitian}

Penelitian ini dilakukan di Bengkel Dinamo Harapan Jaya (Sleman) serta Laboratorium Alsintan, Politeknik Pembangunan Pertanian Yogyakarta - Magelang (Kampus Yogyakarta).

\section{Bahan Penelitian}

Bahan yang digunakan pada penelitian ini antara lain traktor tangan, baterai/aki, motor starter arus searah $(D C)$, roda gila, sekering, relay, saklar, kunci kontak, kabel listrik, lampu indikator, besi siku, besi pipa, adjuster, as shock, sliding bearing, pillow block bearing, engkol modifikasi, pegas tarik, roda, serta baut, mur, dan ring.

\section{Alat Penelitian}

Alat yang digunakan pada penelitian ini antara lain roll meter, stopwatch, dynamometer, tachometer, autocad, gerinda listrik, las listrik, bor listrik, toolbox, timbangan, serta wattmeter.

\section{Prosedur Penelitian}

Prosedur penelitian merupakan cerminan dari setiap tahapan penelitian yang harus dilakukan dan dibuat secara sistematis agar mudah dipahami oleh pembaca. Pada penelitian ini, prosedur penelitiannya ditampilkan pada Gambar 1.

\section{Data Operator}

Dilakukan pengukuran berat badan operator menggunakan timbangan. Sampel operator yang ditimbang berat badannya yaitu 5 orang laki-laki dan diperoleh nilai rata-rata sebesar $67 \mathrm{~kg}$. Nilai rata-rata berat badan kemudian dikalikan dengan $1 \mathrm{kkal} / \mathrm{jam}$ agar dapat diketahui nilai metabolisme basal dari operator laki-laki. Sedangkan apabila operatornya perempuan dikalikan dengan 0,9 kkal/jam. Perkiraan nilai beban kerja menggunakan SNI 7269 Tahun 2009.

\section{Data Traktor Tangan}

Traktor tangan yang digunakan sebagai bahan penelitian adalah traktor tangan merk Yanmar tipe YZC-L dengan fungsi penggunaan rotari. Traktor tangan tersebut memiliki daya maksimal $10,50 \mathrm{hp}$. Roda gila yang digunakan berjenis polos dengan spesifikasi berat $40 \mathrm{~kg}$, jari-jari luar $\left(r_{o}\right) 0,19 \mathrm{~m}$, jari-jari dalam $\left(r_{j}\right) 0,02$ $\mathrm{m}$, lebar $(h) 0,05 \mathrm{~m}$, serta rata-rata kecepatan putar (n) minimal 393,55 rpm. Engkol tangan yang digunakan 
terbuat dari besi tuang dengan spesifikasi diameter luar $\left(d_{o}\right) 0,03 \mathrm{~m}$, diameter dalam $\left(d_{i}\right) 0,02 \mathrm{~m}$, panjang $(r)$ $0,17 \mathrm{~m}$, rata-rata gaya $(F)$ dengan dekompresi 80,61
$\mathrm{N}$, rata-rata gaya $(F)$ tanpa dekompresi $118,37 \mathrm{~N}$, serta rata-rata waktu kerja $(t) 6,92$ detik.

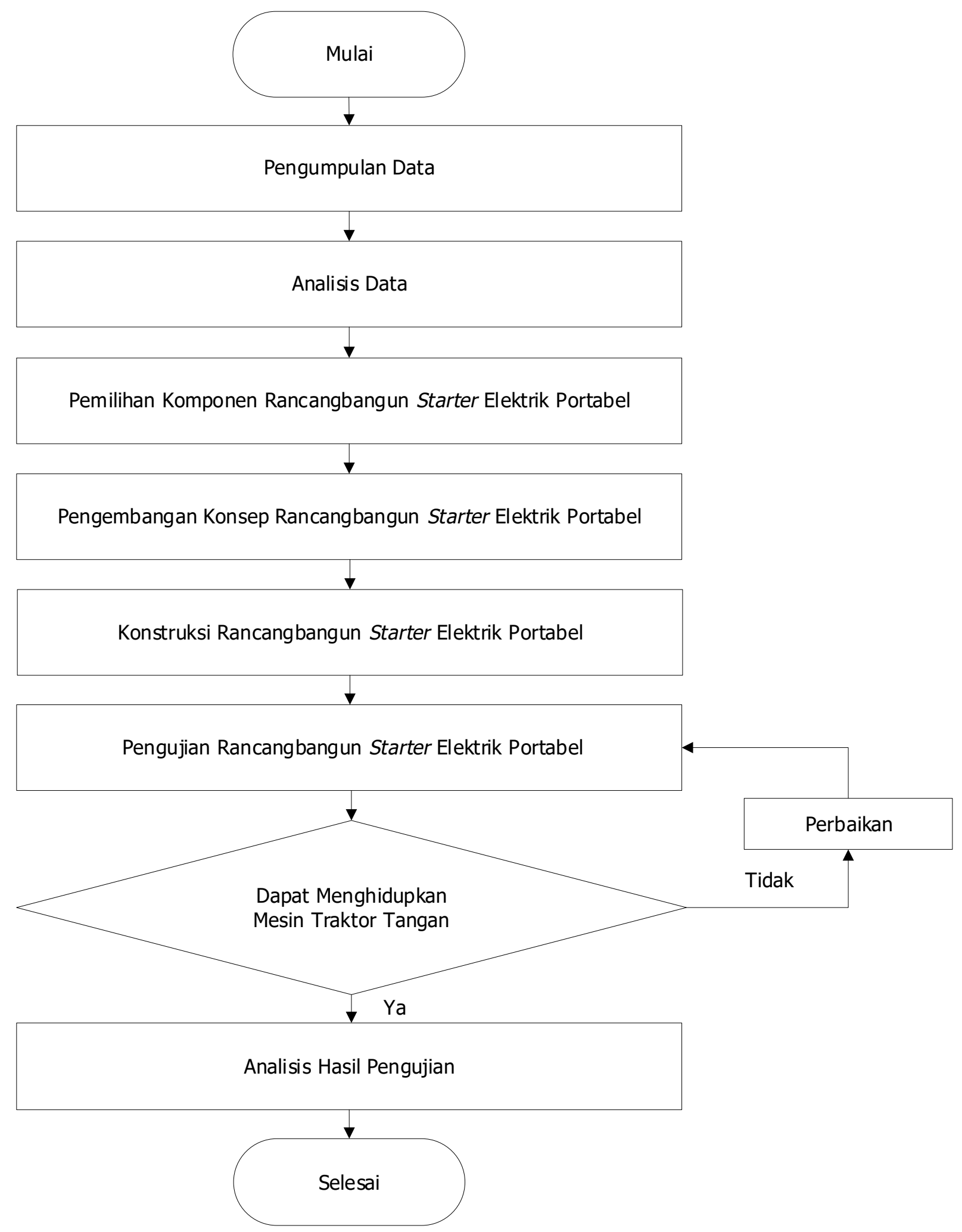

Gambar 1. Prosedur penelitian 


\section{Perhitungan Beban Kerja (Operator)}

Menurut Badan Standardisasi Nasional (2009), beberapa langkah untuk mengetahui nilai beban kerja (operator) adalah dengan menghitung rerata beban kerja (rerata $B K$ ) yang ditampilkan pada Persamaan 1, metabolisme basal (MB) yang ditampilkan pada Persamaan 2 atau 3 (laki-laki atau perempuan), dan total beban kerja (Total BK) yang ditampilkan pada Persamaan 4.

\section{Perhitungan Input Energi Mesin Traktor Tangan}

Kebutuhan input energi minimal pada setiap kali proses starting untuk dapat menghidupkan mesin traktor tangan dihitung menggunakan rumus energi kinetik (EK) yang ditampilkan pada Persamaan 8 . Syarat yang harus diketahui nilai dari beberapa parameter terkait, antara lain frekuensi putaran $(f)$ yang ditampilkan pada
Persamaan 5, kecepatan sudut () yang ditampilkan pada Persamaan 6, dan momen inersia ( $I$ ) yang ditampilkan pada Persamaan 7 (Khurmi dan Gupta, 2005).

\section{Perhitungan Kebutuhan Daya Mesin Traktor Tangan}

Langkah untuk menghitung kebutuhan daya $(P)$ minimal mesin traktor tangan melalui perlakuan dengan dekompresi dan tanpa dekompresi adalah dengan mengukur kecepatan putar $(n)$ minimal menggunakan tachometer dan menghitung torsi ( $T$ ) awal melalui perlakuan dengan dekompresi dan tanpa dekompresi berdasarkan Persamaan 9 . Nilai besaran gaya $(F)$ yang dibutuhan untuk menghitung torsi $(T)$ awal diukur menggunakan dynamometer. Rumus perhitungan daya $(P)$ ditampilkan pada Persamaan 10 (Khurmi dan Gupta, 2005).

Rerata $B K=\left(B K_{1} \cdot T_{1}\right)+\left(B K_{2} \cdot T_{2}\right)+\cdots+\left(B K_{n} \cdot T_{n}\right) /\left(T_{1}+T_{2}+\cdots+T_{n}\right) x 60 \mathrm{kkal} / \mathrm{jam}$

Rerata $B K=$ Rerata beban kerja $(\mathrm{kkal} / \mathrm{jam}), B K_{1}, B K_{2}, \ldots, B K_{n}=$

Beban kerja 1, 2, hingga ke-n, dan $T_{1}, T_{2}, \ldots, T_{n}=$ Waktu kerja 1, 2, hingga ke-n (menit).

$M B_{\text {laki-laki }}=1 \mathrm{kkal} / \mathrm{jam} \times B B$

$M B_{\text {perempuan }}=0,9 \mathrm{kkal} / \mathrm{jam} \times B B$

$M B=$ Metabolisme basal (kkal/jam), dan $B B=$ Berat badan $(\mathrm{kg})$.

Total $B K=$ Rerata $B K+M B$

Total $B K=$ Total beban kerja $(\mathrm{kkal} / \mathrm{jam})$, Rerata $B K=$ Rerata beban kerja (kkal/jam), dan $M B=$ Metabolisme basal $(\mathrm{kkal} / \mathrm{jam})$.

$f=n / 60$

$f=$ Frekuensi putaran $(\mathrm{Hz}), n=$ Kecepatan putar $(\mathrm{rpm})$, dan $60=$ Waktu dalam detik.

$\omega=2 . \pi \cdot f$

$\omega=$ Kecepatan sudut (rad/detik), $\pi=3,14$, dan $f=$ Frekuensi $(\mathrm{Hz})$.

$I=1 / 2 \cdot m \cdot\left(r_{o}^{2}-r_{i}^{2}\right)$

$I=$ Momen inersia $\left(\mathrm{kg} \cdot \mathrm{m}^{2}\right), m=$ Massa $(\mathrm{kg}), r_{o}=$ jari-jari luar $(\mathrm{m})$, dan $r_{i}=$

Jari-jari dalam (m).

$E K=1 / 2 \cdot I \cdot \omega^{2}$

$E K=$ Energi kinetik roda gila (Joule), $I=$ Momen inersia $\left(\mathrm{kg} \cdot \mathrm{m}^{2}\right)$, dan

$\omega=$ Kecepatan sudut (rad/detik).

$T=F \cdot r$

$T=$ Torsi (N.m), $F=$ Gaya (N), dan $r=$ Jarak benda ke pusat rotasi (m).

$P=T \cdot 2 \pi \cdot n / 60$

$P=$ Daya (watt), $T=$ Torsi (N.m), $n=$ Kecepatan putar (rpm), $\pi=3,14$, dan $60=$ Waktu dalam detik. 


\section{HASIL DAN PEMBAHASAN}

\section{Hasil Perhitungan Beban Kerja (Operator) dan Input Energi Mesin Traktor Tangan}

Hasil perhitungan beban kerja (operator) dari penggunaan engkol tangan dan starter elektrik portabel untuk menghidupkan mesin traktor tangan, masingmasing sebesar 1.360,11 Joule dan 264,56 Joule. Sementara itu, hasil perhitungan input energi mesin traktor tangan diperoleh nilai sebesar 627,80 Joule $(\approx$ 0,17 watt jam).

\section{Hasil Perhitungan Kebutuhan Daya untuk Starter Mesin Traktor Tangan}

Hasil perhitungan kebutuhan daya $(P)$ minimal pada mesin traktor tangan melalui perlakuan dekompresi dan perlakuan daya dekompresi, masing-masing sebesar 572,78 watt $(\approx 0,74 \mathrm{hp})$ dan 841,75 watt $(\approx 1,09$ hp). Nilai daya $(P)$ minimal tesebut digunakan sebagai dasar untuk memilih komponen utama, yang kemudian diikuti dengan menentukan komponen pendukung dan mekanisme penggerak yang dibutuhkan.

\section{Pemilihan Komponen Starter Elektrik Portabel}

Komponen utama pertama adalah baterai/aki jenis basah dengan spesifikasi minimal sebesar 12 volt 50 ampere jam (600 watt jam) untuk perlakuan dekompresi. Perlakuan tanpa dekompresi menggunakan 12 volt 75 ampere jam (900 watt jam). Baterai/aki jenis basah dipilih karena harganya yang lebih murah. Kebutuhan tegangannya dipilih sebesar 12 volt karena tegangan minimal baterai/aki untuk starter elektrik adalah 10 volt (Aprilianto, 2016). Komponen utama kedua adalah motor starter arus searah $(D C)$ jenis seri dengan spesifikasi minimal sama dengan kebutuhan penggunaan pada baterai/aki. Motor starter arus searah $(D C)$ jenis seri dipilih karena memiliki torsi starting yang paling tinggi (Nugroho dan Agustina, 2015). Setelah itu, dilanjutkan menentukan komponen pendukung serta mekanisme penggerak yang dibutuhkan.

\section{Pengembangan Konsep Sarter Elektrik Portabel}

Berdasarkan pemilihan dan penjelasan komponen utama, serta penentuan komponen pendukung dan mekanisme penggeraknya, maka pengembangan konsep awal dan akhir pada penelitian ini ditampilkan pada Gambar 2 dan 3.

Adanya engkol modifikasi dimaksudkan sebagai pengganti engkol tangan yang terbuat dari besi tuang. Engkol modifikasi terbuat dari material baja ST 40 karena memiliki struktur bahan yang lebih kuat dari besi tuang. Menurut Zacoeb (2015), besi tuang memiliki kuat tarik minimum sebesar $50 \mathrm{Mpa}$, sedangkan baja ST 40 memiliki kuat tarik minimum sebesar $400 \mathrm{MPa}$. Adanya roda gila bergigi dimaksudkan sebagai penghubung antara motor starter arus searah $(D C)$ jenis seri dengan as shock dan engkol modifikasi. Menurut Jama dkk. (2008), roda gila bergigi berfungsi untuk mereduksi kecepatan putar dari motor starter arus searah $(D C)$ jenis seri, sekaligus untuk menghasilkan torsi yang tinggi.

As shock dari besi polos ditujukan untuk penghubung antara roda gila bergigi dengan engkol modifikasi. Panjang as shock sebesar $50 \mathrm{~cm}$, disesuaikan dengan posisi mesin traktor tangan, khususnya pada block gear startingnya agar tidak bertabrakan dengan

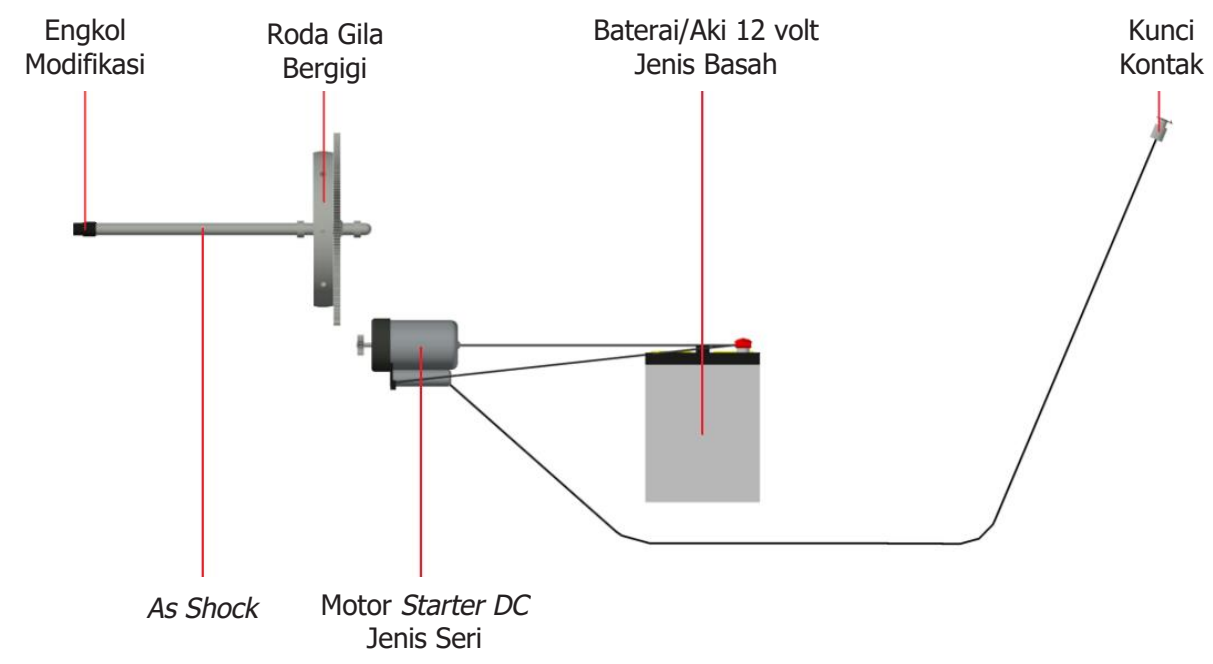

Gambar 2. Pengembangan konsep awal starter elektrik portabel 
bagian roda dari traktor tangan. Adanya kunci kontak dimaksudkan sebagai saklar utama untuk penghubung dan pemutus arus dari baterai/aki 12 volt jenis basah menuju motor starter arus searah (DC) jenis seri serta komponen kelistrikan lainnya (sekering, relay dan lampu indikator).

Pada komponen utama, baterai/aki 12 volt jenis basah memiliki berat $21 \mathrm{~kg}$, motor starter arus searah (DC) jenis seri memiliki berat $6 \mathrm{~kg}$. Sementara itu, roda gila bergigi merupakan komponen pendukung yang memiliki berat paling tinggi, yaitu sebesar 16 kg. Apabila berat dari ketiga komponen tersebut dijumlahkan, maka totalnya menjadi sebesar $43 \mathrm{~kg}$. Hasil penjumlahan tersebut belum ditambahkan dengan berat dari komponen pendukung lainnya, yang jika diestimasikan jumlah totalnya dapat mencapai $70 \mathrm{~kg}$.
Berdasarkan kondisi ini, maka pada pengembangan konsep rancangbangun starter elektrik portabel membutuhkan komponen pendukung berupa roda yang berfungsi untuk mempermudah dalam mobilisasi starter elektrik portabel. Roda terbuat dari material besi agar tahan lama. Roda ini harus mampu menahan berat dari starter elektrik portabel secara keseluruhan. Roda memiliki pegangan (handle) yang berfungsi untuk mempermudah dalam menarik dan mendorong pada saat mobilisasi. Selain itu, roda sebagai tempat untuk meletakkan kunci kontak, saklar, dan lampu indikator.

\section{Konstruksi Starter Elektrik Portabel}

Konstruksi starter elektrik portabel dilakukan berdasarkan pengumpulan dan analisis data rancangbangun, penentuan komponen utama,

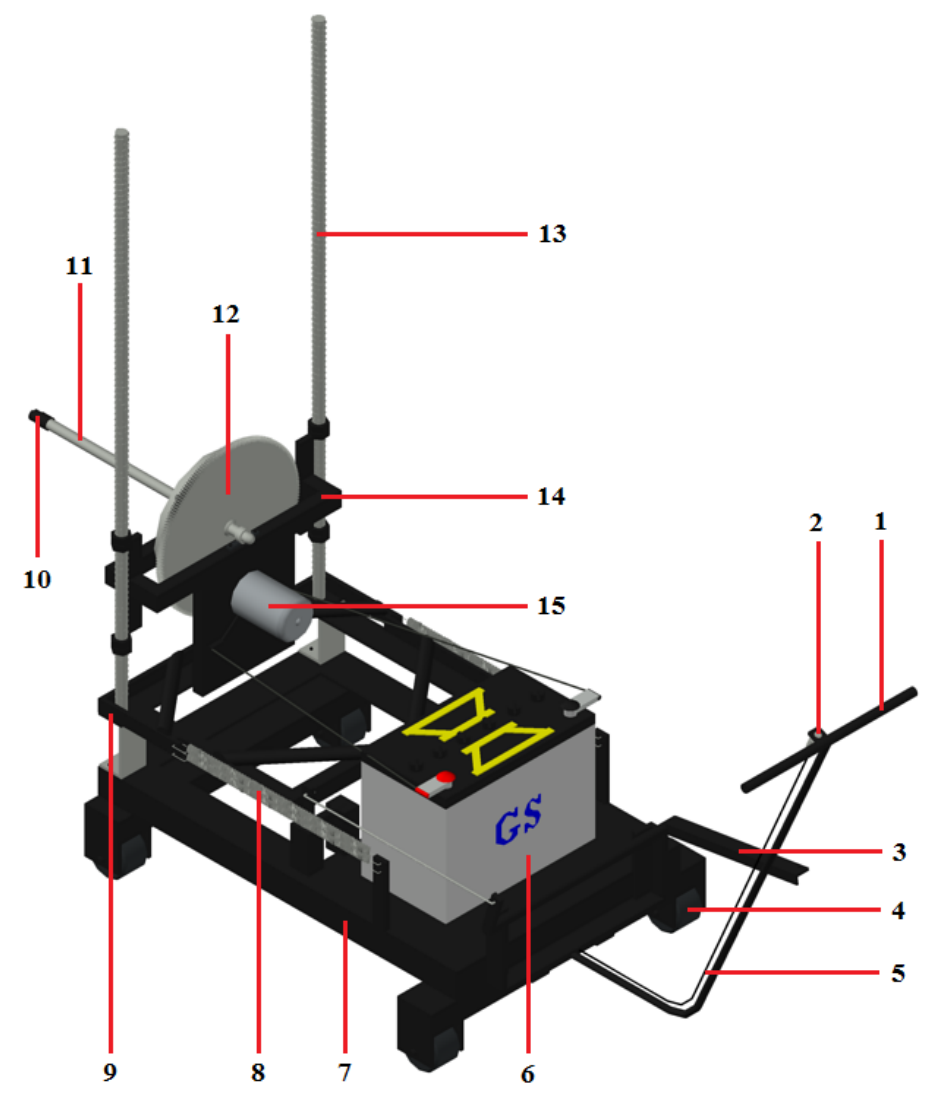

Gambar 3. Pengembangan konsep akhir starter elektrik portabel

Keterangan:

1. Pegangan (handle)

2. Kunci kontak

3. Pedal kopling

4. Roda

5. Kabel listrik
6. Baterai/aki 12 volt jenis basah

7. Rangka utama

8. Pegas tarik

9. Rangka kopling

10. Engkol modifikasi
11. As shock

12. Roda gila bergigi

13. Adjuster

14. Rangka roda gila

15. Motor starter $D C$ jenis seri 
komponen pendukung dan mekanisme penggerak rancangbangun, serta penggambaran pengembangan konsep rancangbangun. Menurut Rozaq (1993), beberapa faktor yang perlu diperhatikan dalam rancangbangun (desain) antara lain spesifikasi setiap komponen, cara perakitan antar komponen, mekanisme penggerak, kerapian pengerjaan, biaya pengerjaan, keamanan penggunaan, getaran, kebisingan, bentuk, ukuran, berat, fleksibilitas, ergonomis, dan yang lainnya. Faktor-faktor tersebut memiliki peranan penting untuk menghasilkan sebuah rancangbangun (desain) yang sesuai dengan kebutuhan penggunaan, serta turut mempengaruhi terhadap kebutuhan energi, biaya dan waktu selama proses pembuatannya. Hasil pengukuran dimensi pada penelitian ini ditampilkan pada Gambar 4.

\section{Prinsip Kerja Starter Elektrik Portabel}

Pertama, engkol modifikasi diposisikan menuju block gear starting mesin traktor tangan melalui bantuan adjuster (untuk mengatur tinggi atau rendahnya) serta kopling (untuk mengatur maju atau mundurnya). Kedua, menerapkan perlakuan dekompresi dan perlakuan tanpa dekompresi (untuk kebutuhan penelitian). Ketiga, memfungsikan kunci kontak dengan cara memutarnya ke sebelah kanan agar lampu indikator menyala dengan warna merah. Keempat, memfungsikan saklar dengan cara memutar kunci kontak ke sebelah kanan agar arus dari baterai/aki 12 volt jenis basah mengalir menuju motor starter arus searah (DC) jenis seri. Dari hal ini maka dapat memutar pinion gear yang diteruskan menuju roda gila bergigi yang telah disambungkan dengan as shock dan engkol modifikasi. Terakhir, engkol modifikasi akan memutar gear starting mesin traktor tangan melalui serangkaian mekanisme poros yang diteruskan menuju poros engkol, sehingga dapat menghidupkan mesinnya.

\section{Analisis Hasil Uji Kinerja}

Pengaplikasian perlakuan dekompresi lebih diutamakan daripada tanpa dekompresi, karena dampak yang ditimbulkan masih dapat ditoleransi. Pengaplikasian perlakuan dekompresi membutuhkan 2 orang operator, sedangkan perlakuan tanpa dekompresi cukup membutuhkan 1 orang operator. Dampak

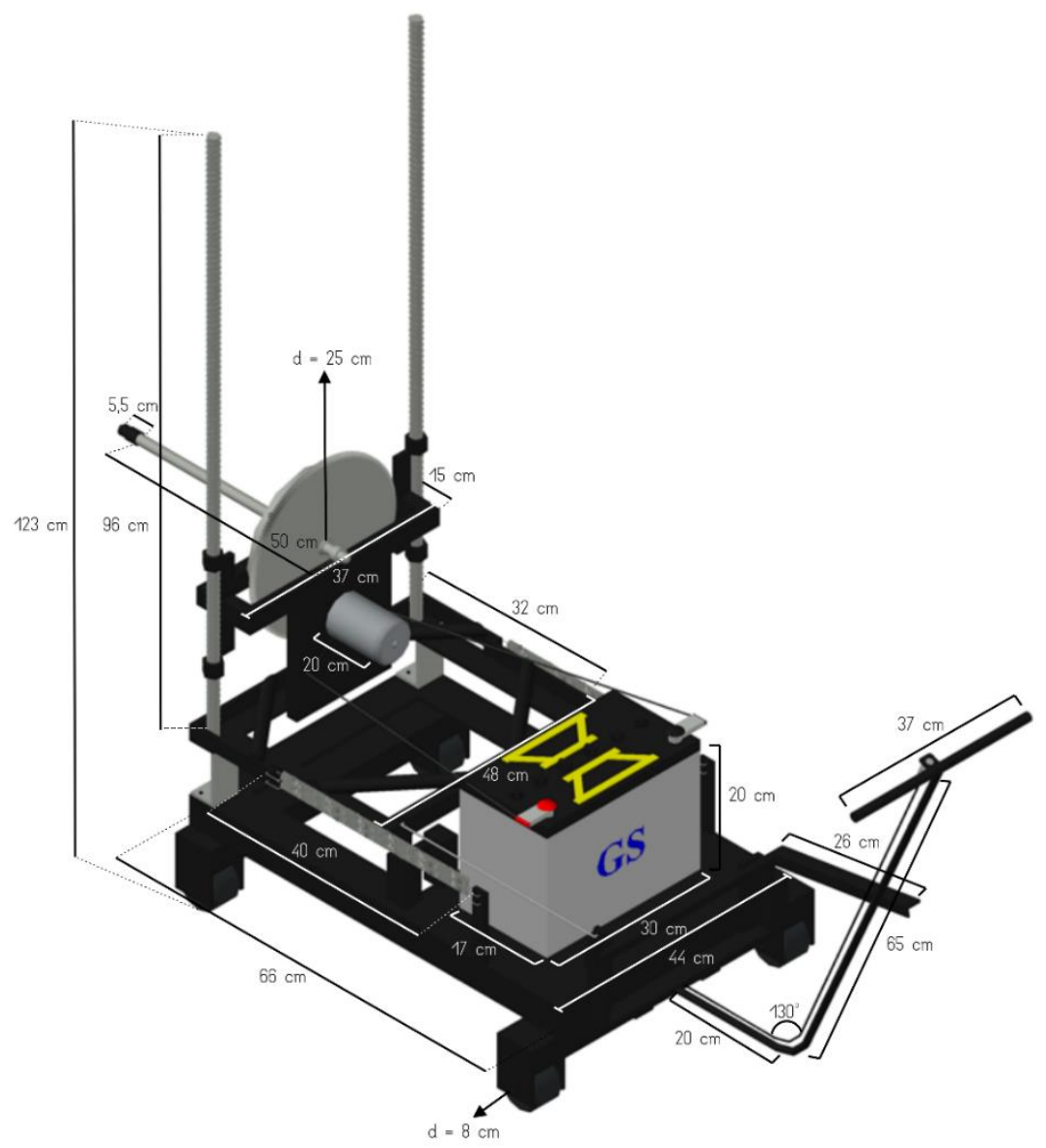

Gambar 4. Pengukuran dimensi starter elektrik portabel 
yang ditimbulkan dari perlakuan dekompresi berupa hentakan halus yang tidak mengakibatkan kerusakan pada komponen mesin traktor tangan, meskipun kondisi tersebut baru dilakukan pada proses pengujian awal. Sementara itu, dampak yang ditimbulkan dari perlakuan tanpa dekompresi berupa hentakan kasar yang mengakibatkan terjadinya kerusakan pada beberapa komponen mesin traktor tangan ketika dilakukan secara terus menerus, yaitu block gear startingnya pecah serta gear startingnya aus. Hentakan terjadi karena energi yang disalurkan dari starter elektrik portabel menuju mesin traktor tangan tidak bertahap, seperti pada penggunaan engkol tangan. Khusus pada perlakuan tanpa dekompresi, timbulnya hentakan kasar juga disebabkan adanya pemampatan udara dalam mesin traktor tangan maupun alsintan lain.

Penggunaan starter elektrik portabel lebih baik dibandingkan penggunaan engkol tangan karena nilai rata-rata waktu kerjanya lebih cepat, yaitu selama 1,88 detik dibandingkan 6,92 detik. Hasil penelitian ini menunjukkan bahwa penyaluran energi pada penggunaan starter elektrik portabel lebih besar. Kondisi ini menyebabkan lebih cepat dalam mencapai kebutuhan kecepatan putar minimal mesin traktor tangan. Penggunaan starter elektrik portabel melalui perlakuan tanpa dekompresi, sedangkan penggunaan engkol tangan melalui perlakuan dekompresi. Hal tersebut disebabkan starter elektrik portabel dirancang menggunakan sumber energi yang berasal dari baterai/ aki 12 volt dan dibantu adanya motor starter arus searah (DC). Sedangkan engkol tangan dirancang menggunakan sumber energi yang berasal dari operator. Selain itu, roda gila yang digunakan pada konstruksi starter elektrik portabel beratnya lebih ringan dibandingkan roda gila mesin traktor tangan.

Penggunaan starter elektrik portabel lebih baik dibandingkan penggunaan engkol tangan. Karena nilai rata-rata beban kerja operator lebih rendah, yaitu sebesar 264,56 Joule dibandingkan manual sebesar $1.360,11$ Joule. Nilai ini menunjukkan bahwa beban kerja (operator) yang dilakukan pada penggunaan starter elektrik portabel lebih ringan, sehingga operator lebih mudah untuk menghidupkan mesin traktor tangan. Hal tersebut disebabkan beban kerja (operator) yang dilakukan pada penggunaan starter elektrik portabel hanya saat persiapan serta memutar kunci kontak. $\mathrm{Hal}$ ini dilakukan untuk menghidupkan mesin traktor tangan akan dilakukan oleh starter elektrik portabel itu sendiri. Pada kasus engkol tangan, maka menjadi lebih berat karena operator harus melakukannya secara keseluruhan, yaitu mulai dari persiapan hingga memutar engkol tangan sampai mesin traktor tangan dapat dihidupkan.

Nilai kecepatan putar minimal yang dibutuhkan untuk menghidupkan mesin traktor tangan kurang lebih sebesar $360 \mathrm{rpm}$, yaitu masing-masing sebesar $363,20 \mathrm{rpm}$ dan 366,90 rpm melalui penggunaan starter elektrik portabel dan penggunaan engkol tangan. Pada penggunaan engkol tangan, juga telah dilakukan pengukuran nilai kecepatan putar dibawah 360 rpm (tepatnya sebesar 350,30 rpm), yang hasilnya mesin traktor tangan hanya dapat hidup beberapa detik saja sebelum mati dengan sendirinya. Hal tersebut menunjukkan bahwa pada saat menghidupkan mesin traktor tangan, penyaluran bahan bakar melalui pengaturan gas memiliki peranan penting dalam memenuhi kebutuhan kecepatan putar minimal dimaksud.

Pengaplikasian perlakuan dekompresi pada penggunaan engkol tangan dengan perlakuan tanpa dekompresi pada penggunaan starter elektrik portabel memiliki perbedaan kebutuhan daya yang cukup signifikan, yaitu sebesar 0,17 watt jam dibandingkan 0,68 watt jam (perbandingan 1:4). Hal tersebut disebabkan pada perlakuan tanpa dekompresi terdapat pemampatan udara di dalam mesin traktor tangan yang menyebabkan torsinya menjadi semakin tinggi, sehingga berdampak pada putaran engkolnya yang menjadi semakin berat. Oleh sebab itu, pengaplikasian perlakuan tanpa dekompresi menggunakan engkol tangan untuk menghidupkan mesin traktor tangan tidak akan mampu dilakukan melalui energi operator.

\section{KESIMPULAN}

Hasil uji kinerja menunjukkan bahwa kebutuhan waktu kerja sebesar 1,88 detik, kebutuhan beban kerja (operator) sebesar 264,56 Joule, kebutuhan kecepatan putar sebesar 363,20 rpm serta kebutuhan daya sebesar 0,68 watt jam yang diperoleh melalui pengaplikasian perlakuan tanpa dekompresi. Secara keseluruhan, hasil tersebut menyatakan bahwa penggunaan starter elektrik portabel lebih baik dibandingkan engkol tangan. Berdasarkan uji kinerja pula, pada akhirnya diketahui bahwa pengaplikasian perlakuan dekompresi lebih diutamakan.

\section{UCAPAN TERIMA KASIH}

Terima kasih yang sebesar-besarnya penulis haturkan kepada Menteri Pertanian RI beserta jajarannya karena telah memberikan kepercayaan kepada penulis untuk melanjutkan pendidikan ke jenjang S2 melalui beasiswa Badan Penyuluhan dan Pengembangan SDM 
Pertanian serta Dosen Pembimbing Utama dan Dosen Pembimbing Pendamping I atas segala bimbingan dan arahannya.

\section{KONFLIK KEPENTINGAN}

Tidak ada konflik kepentingan pada penelitian ini.

\section{DAFTAR PUSTAKA}

Aprilianto, R. (2016). Analisis perbedaan sistem startertekanan udara pada KMP Merawan II dan sistem starter elektrik pada KMP Semah di PT ASDP Indonesia Ferry (Persero) cabang Pontianak. Program Studi Teknik Mesin, Fakultas Teknik, Universitas Muhammadiyah Pontianak.

Badan Standardisasi Nasional. (2009). SNI 7269:2009: Penilaian beban kerja berdasarkan tingkat kebutuhan kalori menurut beban kerja. http://www.academia. edu/8178876/ SNI_7269_2009. [23 Januari 2019].

Kementerian Pertanian RI. (2018). Statistik prasarana dan sarana pertanian tahun 2013 - 2017. http://psp. pertanian.go.id/assets/file/2019/Buku\%20Statistik\%20 Ditjen\%20PSP_2013-2017. pdf. [5 April 2018].

Khurmi, R.S., dan Gupta, J.K. (2005). A Text Book of Machine Design (S.I. Units). Eurasia Publishing House, New Delhi.

Meicipto, A., Suprihadi, A., dan Nuryasin, M. (2015). Memperbaiki gangguan motor starter elektrik sepeda motor Honda Astrea Grand 100 cc tahun 1997. Jurusan Teknik Mesin, Politeknik Harapan Bersama Tegal. http:// ejournal.poltektegal.ac.id/index.php/nozzle/ article/ view/157/156. [24 Oktober 2018].
Najib, I. (2013). Mekanisme katup pada mesin Suzuki G15. Program Studi Diploma 3 Teknik Mesin, Jurusan Teknik Mesin, Fakultas Teknik, Universitas Negeri Semarang.

Nugraha, D.G. (2014). Perencanaan sistem start pada mesin diesel. Jurusan Teknik Sistem Perkapalan, Fakultas Teknologi Kelautan, Institut Teknologi Sepuluh Nopember Surabaya. http://digilib.its.ac.id/ public/ITSpaper-41262-4209100002-paper.pdf. [14 Desember 2017].

Nugraha, S.A. (2016). Identifikasi keselamatan kerja pada area docking kapal di PPN Palabuhanratu, Kabupaten Sukabumi, Propinsi Jawa Barat. Departemen Pemanfaatan Sumberdaya Perikanan, Fakultas Perikanan dan Ilmu Kelautan, Institut Pertanian Bogor.

Nugroho, N., dan Agustina, S. (2015). Analisa motor DC (Direct Current) sebagai penggerak mobil listrik. Mikrotiga. Volume 2. Nomor 1: 30.

Rozaq, A. (1993). Pengembangan Mesin Pertanian. Bahan Kuliah Mahasiswa S2, Program Studi Mekanisasi Pertanian, Fakultas Pasca Sarjana, Universitas Gadjah Mada Yogyakarta.

Zacoeb, A. (2015). Iron and steel. Departemen Teknik Sipil, Fakultas Teknik, Universitas Brawijaya Malang. http:// zacoeb.lecture.ub.ac.id/files/2015/03/Sesi-3-Iron-Steel. pdf. [19 Desember 2018]. 